\title{
An update on the general management approach to common vasculitides
}

\author{
Authors: Mooikhin Hng, ${ }^{A}$ Sizheng S Zhao ${ }^{B}$ and Robert J Moots ${ }^{C}$
}

Primary systemic vasculitides (PSV) are multisystem diseases associated with high morbidity and mortality, particularly if not treated in a timely manner. In recent decades, clinical trials have delivered considerable evidence to underpin optimal diagnostic and therapeutic approaches. This article provides a brief overview of PSV in adults, focusing on the latest updates and recommendations for the management of antineutrophil cytoplasmic antibody-associated vasculitis and giant cell arteritis.

\section{Introduction}

Primary systemic vasculitides (PSV) are a group of rare, chronic diseases characterised by inflammation of the blood vessels. ${ }^{1}$ Vessels of any size in any organ can be affected. The disease spectrum ranges from mild, localised disease to potentially life- or organ-threatening manifestations. Due to their heterogeneity and rarity, the recognition and management of vasculitis poses a considerable challenge to many physicians. In this review, we begin with a general overview of vasculitis in adults, including classification and general management approaches. We then focus on two comparatively common diseases, antineutrophil cytoplasmic antibody (ANCA)-associated vasculitis (AAV) and giant cell arteritis (GCA), with the latest update on their management.

\section{Types of vasculitis}

Although this review focuses on PSV, the general approach to vasculitis requires consideration and exclusion of mimics and secondary vasculitis. Vasculitis may be mimicked by reactions to drugs, infections, malignancy or thromboembolic disease. Secondary vasculitis can develop in the context of inflammatory rheumatic diseases, such as rheumatoid arthritis and systemic lupus erythematosus. It is important to distinguish these from

Authors: ${ }^{A}$ international training fellow, Aintree University Hospital, Liverpool, UK; ${ }^{\text {B }}$ Clinical research fellow, Aintree University Hospital, Liverpool, UK and University of Liverpool, Liverpool, UK; C professor of rheumatology, Aintree University Hospital, Liverpool, UK and Edge Hill University, Liverpool, UK
PSV, as their management can differ completely; for example, immunosuppressive medication used for the treatment of presumed PSV may aggravate infectious diseases. Therefore, it is imperative to exclude other problems before making a diagnosis of PSV. Table 1 provides a summary of some mimics. ${ }^{2,3}$

Currently, there are no validated diagnostic criteria for PSV. The Chapel Hill Consensus Conference (CHCC) in 2012 updated the definitions and nomenclature for vasculitis. Vasculitides are categorised primarily by vessel size, together with aetiology, pathogenesis, pathology, demographics and clinical features (Fig 1). The ongoing Diagnostic and Classification Criteria in Vasculitis Study

\section{Key points}

Vasculitis should be suspected in any systemically ill patients with multiorgan dysfunctions, especially in patients with no conventional cardiovascular risk factors who presented with organ ischaemia symptoms.

The principles of managing antineutrophil cytoplasmic antibody-associated vasculitis are to induce and maintain disease remission using a combination of glucocorticoids and immunosuppressants.

Rituximab is an efficacious treatment option for remission induction and maintenance among patients with organthreatening, life-threatening or relapsing disease. It is preferable when cyclophosphamide is contraindicated or fertility issue is a concern.

Colour Doppler ultrasound of temporal or axillary arteries has similar diagnostic values as temporal artery biopsy in giant cell arteritis.

Tocilizumab is a new therapeutic option for relapsing or refractory giant cell arteritis that dramatically reduces cumulative glucocorticoid exposure.

KEYWORDS: Vasculitis, ANCA, giant cell arteritis, tocilizumab, rituximab

DOI: $10.7861 /$ clinmed.2020-0747 
Table 1. Vasculitis mimics

$\begin{array}{ll}\text { Vasculitis mimics } & \text { Example } \\ \text { Infections } & \text { Infective endocarditis } \\ & \text { Bacteria eg meningococcaemia or } \\ & \text { gonococcaemia } \\ & \text { Spirochetes } \\ & \text { Fungi } \\ & \text { Mycobacteria } \\ & \text { Viruses } \\ & \text { Ergotamine } \\ & \text { Cocaine } \\ \text { Drugs/therapy } & \text { Phenylpropanolamine } \\ & \text { Warfarin } \\ & \text { Radiation therapy } \\ & \text { Leukaemia cutis } \\ & \text { Plasma cell dyscrasia } \\ & \text { Metastatic carcinoma } \\ & \text { Paraneoplastic syndrome } \\ & \text { Lymphoma, especially involving nasal or } \\ \text { Malignancy } & \text { paranasal cavity } \\ & \text { Atrial myxoma } \\ \text { Cholesterol emboli from an atheroma } & \text { Antiphospholipid syndrome } \\ \text { Thrombotic thrombocytopenic purpura } \\ \text { Thromboembolic } \\ \text { Sickle cell disease } \\ \text { Procoagulant states } \\ \text { Calciphylaxis } \\ \text { Fibromuscular dysplasia } \\ \text { Amyloid angiopathy } \\ \text { Neurofibromatosis type I } \\ \text { Coarctation of the aorta } \\ \text { Chronic ergotism } \\ \text { Scurvy } \\ \text { Sweet's syndrome } \\ \text { Köhlmeier-Degos disease } \\ \end{array}$

(DCVAS) Project is anticipated to develop and validate diagnostic criteria and improve classification criteria for PSV. ${ }^{4}$

\section{Approach to a patient with possible PSV}

Diagnosis of PSV is based on a combination of clinical, laboratory, histopathological and radiological features. There are several clinical manifestations that should raise suspicion of vasculitis. The most common are constitutional symptoms such as fever, malaise, unintentional weight loss and anorexia. These features are not unique to PSV; chronic infection, malignancy and autoimmune connective tissue diseases may present similarly. Symptoms indicating organ ischaemia (eg limb claudication, digital ulcer, stroke or myocardial infarction) are more specific, especially if they occur in young patients without conventional cardiovascular risk factors. Vasculitis should be suspected in constitutionally ill patients with multiorgan dysfunctions.

A systematic and comprehensive history (Table 2) and examination (Fig 2) are essential. Laboratory tests are crucial for excluding mimics or secondary vasculitis and determining extent of organ involvement. The more specific serological, histopathological

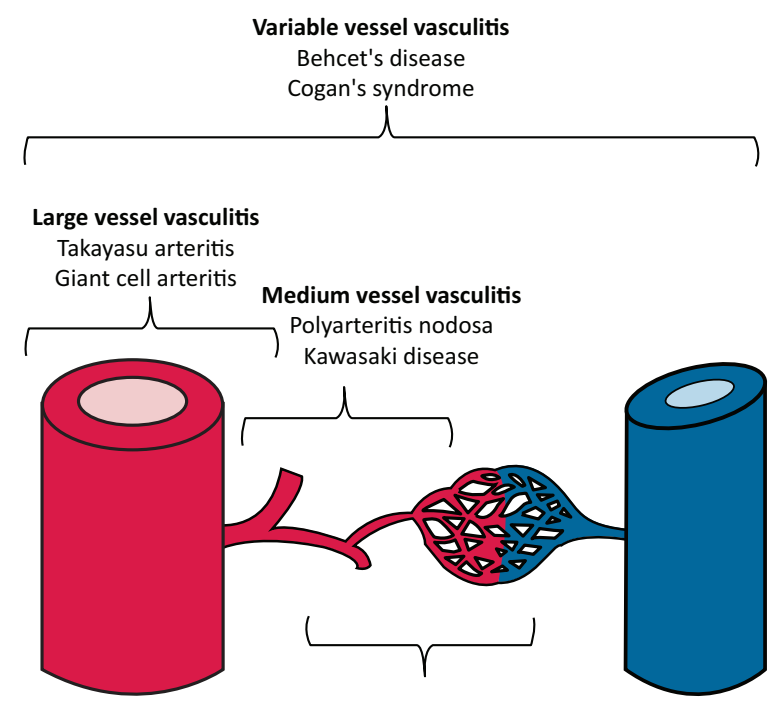

Small vessel vasculitis

Antineutrophil cytoplasmic antibody-associated vasculitis: microscopic polyangitis

granulomatosis with polyangiitis (Wegener's)

eosinophilic granulomatosis with polyangiitis (Churg-Strauss) Immune complex small vessel vasculitis:

antiglomerular basement membrane disease cryoglobulinaemia vasculitis

immunoglobulin A vasculitis (Henoch-Schönlein)

hypocomplementemic urticarial vasculitis

Fig 1. Types of vasculitis categorised according to the distribution of major vessel involvement.

and angiographic investigations are helpful in categorising PSV (Table 3).

\section{AAV}

$\mathrm{AAV}$ is characterised by necrotising vasculitis predominantly affecting small vessels, with few or no immune deposits. It is usually associated with ANCA specific for myeloperoxidase (MPO-ANCA) or proteinase 3 (PR3-ANCA) and commonly involves the respiratory tract and kidneys. ${ }^{1}$

The estimated prevalence of AAV in England is 14.6/100,000 population. The median age of these patients is 65.3 years with approximately equal gender ratio. The prevalence of granulomatosis with polyangiitis (GPA) is $9.97 / 100,000$, microscopic polyangiitis (MPA) is $1.40 / 100,000$ and eosinophilic granulomatosis with polyangiitis (EGPA) is $3.18 / 100,000 .^{5}$

\section{Management of AAV}

The British Society for Rheumatology (BSR) and British Health Professionals in Rheumatology (BHPR) published revised guidelines for the management of adults with AAV in 2014. ${ }^{6}$ The European League Against Rheumatism (EULAR) and European Renal Association - European Dialysis and Transplant Association (ERA-EDTA) and Canadian Vasculitis Research Network (CanVasc) updated similar recommendations in 2016. ${ }^{7,8}$ The Brazilian Society of Rheumatology (SBR) had published recommendations on the induction therapy of AAV in $2017 .^{9}$

These latest guidelines and recommendations have simplified the stratification of AAV disease severity into non-severe and 
Table 2. Summary of clinical history for patient with probable vasculitides

\begin{tabular}{|c|c|}
\hline History & Descriptions \\
\hline General & $\begin{array}{l}\text { Onset of symptoms, progression } \\
\text { Preceding infection, illness or trauma } \\
\text { Previous medical illness } \\
\text { Previous drug usage } \\
\text { Family history of autoimmune rheumatic } \\
\text { disease or chronic hepatitis infection } \\
\text { Travel history } \\
\text { Occupational history } \\
\text { Recreational drug consumption or high-risk } \\
\text { behaviour }\end{array}$ \\
\hline $\begin{array}{l}\text { Constitutional } \\
\text { symptoms }\end{array}$ & $\begin{array}{l}\text { Fever, sweats } \\
\text { Weight loss, anorexia } \\
\text { Malaise, fatigue }\end{array}$ \\
\hline Skin, extremities & $\begin{array}{l}\text { New, persistent skin rashes } \\
\text { Raynaud's phenomenon } \\
\text { Digital ulcer } \\
\text { Cutaneous ulcer }\end{array}$ \\
\hline Musculoskeletal & $\begin{array}{l}\text { Myalgia, muscle weakness, stiffness } \\
\text { Arthralgia }\end{array}$ \\
\hline $\begin{array}{l}\text { Ear, nose and } \\
\text { throat }\end{array}$ & $\begin{array}{l}\text { Persistent, recurrent, blood-stained nasal } \\
\text { discharge or epistaxis } \\
\text { Nasal crusting } \\
\text { Sinusitis } \\
\text { Nasal bridge collapse } \\
\text { Ear discharge } \\
\text { Hearing impairment }\end{array}$ \\
\hline Eye & $\begin{array}{l}\text { Painful, red eye } \\
\text { Sight loss, changes to colour vision } \\
\text { Diplopia }\end{array}$ \\
\hline Nervous system & $\begin{array}{l}\text { Wrist drop, foot drop } \\
\text { Stroke } \\
\text { Seizure } \\
\text { Headache }\end{array}$ \\
\hline Extracranial & $\begin{array}{l}\text { Scalp tenderness / hyperaesthesia } \\
\text { Jaw claudication, tongue claudication }\end{array}$ \\
\hline Pulmonary & $\begin{array}{l}\text { Asthma } \\
\text { Breathlessness } \\
\text { Haemoptysis }\end{array}$ \\
\hline Cardiovascular & $\begin{array}{l}\text { Limb claudication } \\
\text { Chest pain }\end{array}$ \\
\hline Gastrointestinal & $\begin{array}{l}\text { Abdominal pain } \\
\text { Diarrhoea } \\
\text { Haematemesis, melaena, haematochezia }\end{array}$ \\
\hline Renal & $\begin{array}{l}\text { Frothy urine, haematuria } \\
\text { Hypertension }\end{array}$ \\
\hline Genitourinary & Scrotal pain \\
\hline
\end{tabular}

severe groups, namely, 'non-organ threatening disease' and 'organ- or life-threatening disease'.

The general principles of managing AAV are to induce and maintain disease remission using the least cytotoxic medications. Latest BSR/BHPR and EULAR/ERA-EDTA recommendations also

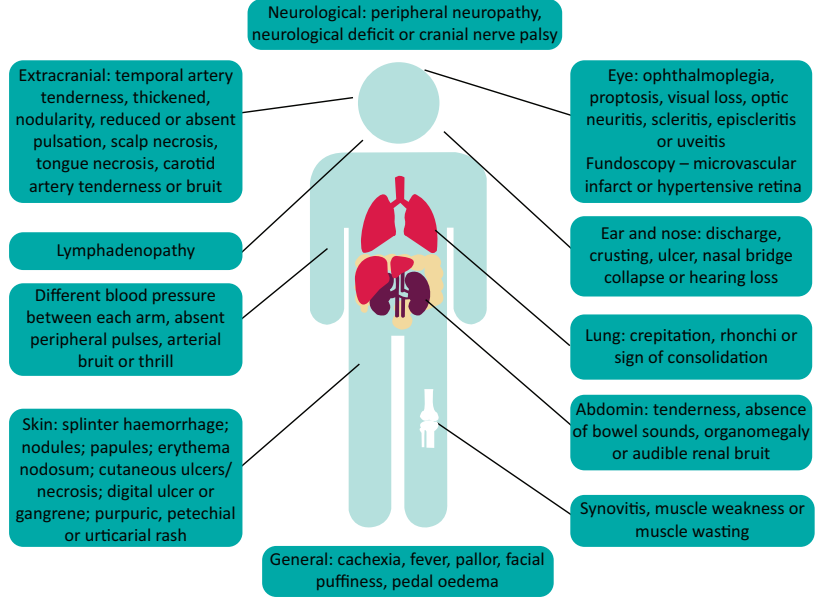

Fig 2. Summary of possible clinical findings in patients with primary systemic vasculitides.

highlight the importance of patient education and participation in disease management.

\section{Remission induction}

\section{Organ- or life-threatening AAV}

Latest guidelines advocate combination of either cyclophosphamide (CYC) or rituximab (RTX) with glucocorticoids in inducing remission in patients with organ- or life-threatening AAV.

In the CYCLOPS study, pulsed CYC was associated with fewer leukopenia episodes and lower cumulative dose than oral regimens and thus deemed to have lower toxicity. ${ }^{10}$ Although pulsed CYC was associated with a higher relapse risk than oral CYC in an extended follow-up study, it was not associated with increased mortality or long-term morbidity. ${ }^{11}$ Oral CYC is therefore no longer a preferred choice for induction therapy in BSR/BHPR and EULAR/ERA-EDTA recommendations, but is still considered as an option in CanVasc and SBR recommendations. ${ }^{6-9}$ BSR/BHPR recommends intravenous CYC $15 \mathrm{mg} / \mathrm{kg}$ at 2-week intervals for first three pulses and thereafter at 3-week intervals, reduced for age and renal function. Each course should be a minimum of 3 months but not exceed 6 months. ${ }^{6}$

RTX has emerged as a new remission induction option for severe AAV after it was demonstrated to be non-inferior to CYC in the RAVE and RITUXVAS trials. ${ }^{12,13}$ The RAVE trial, which recruited younger AAV patients with less severe renal disease, demonstrated similar rates of adverse events compared to oral CYC. ${ }^{12}$ RITUXVAS trial, using intravenous CYC as a comparator, showed equivalent sustained-remission and infection rates. ${ }^{13}$ The RITUXVAS 2-year follow-up study showed comparable disease remission, adverse events and mortality. ${ }^{14}$ This B-cell-depleting anti-CD20 monoclonal antibody is now recognised as a first-line alternative by all guidelines, with minor difference in restrictions on its use. The UK National Institute for Health and Care Excellence (NICE) considers RTX to be cost effective in treating AAV. ${ }^{15}$ The BSR/BHPR gives preference to RTX when CYC avoidance is needed, eg pre-existing high cumulative dose of CYC, infection, intolerance, uroepithelial malignancy or infertility concern. ${ }^{6}$ Dosing regimens are either $375 \mathrm{mg} / \mathrm{m}^{2} /$ week for 4 weeks or two infusions of $1 \mathrm{~g}, 2$ weeks apart. $^{6,16}$ The EULAR/ERA-EDTA emphasised the lack of strong data on the use of RTX for EGPA? 
Table 3. Laboratory investigations useful in the evaluation of suspected vasculitides

\section{Preliminary investigations}

Full blood count

Urinalysis, urine protein:creatinine ratio

Renal profile

Liver function test

Creatinine kinase

Fasting lipid profile, fasting blood sugar

C-reactive protein, erythrocyte sedimentation rate

Procalcitonin level

Blood culture

Hepatitis B and hepatitis C screening

HIV test

Other serology such as parvovirus B19, cytomegalovirus or

specific fungal serology test

Antinuclear antibody, antidouble stranded deoxyribonucleic

acid (antidsDNA), extractable nuclear antigen

Antiphospholipid antibodies

Rheumatoid factor

Complements level

Urine toxicology screening

Chest X-ray or computed tomography of the thorax

Sinus X-ray or computed tomography

Electrocardiography, echocardiography

Serum protein electrophoresis, serum free light chains, urine

Bence Jones protein

\section{More specific investigations}

Perinuclear ANCA (pANCA) and cytoplasmic ANCA (cANCA)

Antiproteinase 3 (antiPR3) and antimyeloperoxidase (antiMPO)

antibody

Antiglomerular basement membrane antibody

Serum cryoglobulins

Immunoglobulin E level

Appropriate tissue biopsy

Bronchoscopy, bronchoalveolar lavage

Angiographic examinations

Magnetic resonance angiography / magnetic resonance imaging

Positron emission tomography

Nerve conduction studies or electromyography
High-dose glucocorticoids at $1 \mathrm{mg} / \mathrm{kg} /$ day or equivalent remains the cornerstone of remission induction therapy. The BSR/BHPR recommends intravenous methylprednisolone $250-500 \mathrm{mg}$ to be given prior to or with the first two pulses of $\mathrm{CYC} .{ }^{6}$ CanVasc and SBR recommend intravenous methylprednisolone 500-1,000 mg for 1-3 days as initial part of induction therapy in severe AAV. ${ }^{8,9}$ All guidelines acknowledge little data supporting the benefits of intravenous methylprednisolone in severe AAV. The BSR/BHPR and EULAR/DRA-EDTA recommend tapering prednisolone to 15 mg or 7.5-10 mg at 12 weeks, respectively. Detailed prednisolonetapering protocols have been outlined in CanVasc and SBR recommendations. ${ }^{8,9}$

Newer therapies continue to emerge. The ADVOCATE trial investigated avacopan (a novel orally-administered selective antagonist of complement fragment $\mathrm{C} 5$ a receptor ( $\mathrm{C} 5 \mathrm{aR})$ ) against prednisolone for remission induction, each in combination with CYC or RTX, followed by azathioprine for maintenance. The avacopan combination was non-inferior to prednisolone combination at week 26 and superior in sustained remission at week 52. A remarkable reduction in glucocorticoid-related toxicity was observed in the avacopan arm. ${ }^{17}$

\section{Severe organ-/life-threatening AAV}

The BSR/BHPR, EULAR/ERA-EDTA and SBR recommend consideration of plasma exchange (PLEX) for patients with new or relapsing AAV and severe renal failure (creatinine $>500$ $\mu \mathrm{mol} / \mathrm{L}$ ) or severe diffuse alveolar haemorrhage, in addition to pulsed CYC and glucocorticoids. ${ }^{6,7,9}$ CanVasc recommendations restrict PLEX as adjuvant to patients with severe AAV refractory to standard remission induction therapy. ${ }^{8}$ More data are needed on PLEX efficacy. In the MEPEX trial, PLEX improved rate of renal recovery at 3 months when compared with intravenous methylprednisolone, while patient survival and severe adverse event rates were similar at 12 months. ${ }^{18}$ However PEXIVAS (a factorial trial design comparing PLEX vs no PLEX among patients with severe AAV receiving (YC or RTX) did not show adjuvant PLEX to reduce death or end-stage renal failure after up to 7 years of follow-up. Results did not support a treatment effect for the 191 participants with pulmonary haemorrhage. The design also allowed comparison of reduced vs standard dose glucocorticoid regimens; outcomes were non-inferior when using $50 \%$ reduced glucocorticoids dose. $^{19}$

\section{Localised AAV}

Mycophenolate mofetil (MMF) or methotrexate (MTX) in combination with glucocorticoids are recommended for remission induction in AAV patients without evidence of organ damage. Long-term data from the NORAM study showed that MTX was safe and as effective as oral CYC in achieving remission in nonorgan-threatening AAV, but the median time to relapse and cumulative relapse-free survival were shorter in MTX-treated patients. ${ }^{20}$ In the MYCYC trial, MMF was non-inferior to pulsed CYC for remission induction in patients with AAV but resulted in higher relapse rate, especially in those with PR3-ANCA positivity. ${ }^{21}$ Regarding long-term CYC toxicity, both BSR/BHPR and EULAR/ ERA-EDTA have phased out CYC, instead recommending a combination of glucocorticoids with either MTX (up to 25-30 mg once per week) or MMF (up to $3 \mathrm{~g} /$ day) for localised AAV., CanVasc and SBR recommendations advocate only combination of glucocorticoids and MTX., ${ }^{8,9}$ Generally, MTX dose reduction is 
required in renal impairment and MMF is preferred over MTX in moderate or severe renal impairment. $6,8,9$

\section{Refractory disease}

Treatment for refractory disease remains challenging and should be managed at expert centres. BSR/BHPR and CanVasc favour use of RTX in those who fail to achieve remission with CYC and glucocorticoids. ${ }^{6,8}$ EULAR/ERA-EDTA advocates switching from CYC to RTX or vice versa. ${ }^{7}$ Adjunctive intravenous immunoglobulin has been suggested by BSR/BHPR, EULAR/ERA-EDTA and CanVasc for patients who have refractory disease or persistent low activity. ${ }^{6-8}$ BSR/BHPR and CanVasc recommend mepolizumab (anti-interleukin-5 monoclonal antibody) for refractory EGPA. ${ }^{6,8}$

\section{Remission maintenance}

Once remission is achieved, low-dose glucocorticoids combined with azathioprine, MTX, MMF, leflunomide or RTX are recommended for maintenance by BSR/BHPR, EULAR/ERA-EDTA and CanVasc, with various preferences.

RTX was superior to azathioprine in maintaining remission (after CYC induction) for AAV in the MAINRITSAN trial, where more patients had sustained remission at month 28 with comparable safety. ${ }^{22}$ The advantage of RTX over azathioprine in preventing relapse continued at 60 months' follow-up. ${ }^{23}$ The RITAZAREM trial demonstrated RTX to be superior to azathioprine in achieving sustained-remission among patients with relapsing disease at baseline and given RTX as induction therapy. ${ }^{24}$ The cost of RTX can be prohibitive. BSR released consensus guidelines on the use of RTX for maintenance in new and relapsing AAV following RTX or CYC induction. They advocate the fixed interval dosing, either $500 \mathrm{mg}$ or $1,000 \mathrm{mg}$ administered every 6 months for a period of 2 years. $^{25}$

Azathioprine, the standard-of-care therapy for remission maintenance, was superior to MMF in the IMPROVE study. ${ }^{20}$ Although leflunomide was superior to MTX, it is preferred as a second-line treatment due to its adverse effects profile. ${ }^{6-8,26}$

BSR/BHPR and EULAR/ERA-EDTA recommend at least 24 months of remission maintenance therapy, whereas CanVasc recommends 18 months. ${ }^{6-8}$ Some experts advocate 36 months in patients who are PR3-ANCA positive. ${ }^{7}$ In patients who relapse after a prior course of RTX maintenance, with persistent ANCA positivity, or where the effect of relapse would be organ- or life-threatening despite 2 years of RTX maintenance therapy, an extended duration of RTX up to 5 years could be considered. ${ }^{25}$ If sustained remission is achieved for at least 1 year on maintenance therapy, BSR/BHPR suggests tapering glucocorticoids, followed by withdrawing immunosuppressants 6 months later. ${ }^{6}$

\section{Relapse of AAV}

Latest BSR/BHPR guidelines advocate the use of RTX or further course of CYC in major relapse. ${ }^{6}$ The EULAR/ERA-EDTA and CanVasc more strongly recommend RTX over CYC, given concerned over cumulative CYC dose. ${ }^{7,8}$ RAVE long-term followup data showed that those with severe relapsing disease treated with RTX had superior remission maintenance and fewer severe relapses at 6 and 12 months. ${ }^{27}$ BSR/BHPR, EULAR/ERA-EDTA and CanVasc recommend optimisation or modification of remission maintenance agent and increase glucocorticoid dose for minor relapse, without specifying choice of immunosuppressant and duration of therapy. ${ }^{6-8}$

\section{Long-term follow-up and monitoring}

Long-term follow-up and monitoring for disease relapse and its complications is imperative since $\mathrm{AAV}$ is a chronic relapsing disease. The role of biomarkers (eg ANCA, PR3-ANCA, MPO-ANCA or CD19) in predicting disease relapse requires further research. Regular monitoring and assessment for infections, haemorrhagic cystitis, cancer (ie bladder or cervical), infertility, cardiovascular and thromboembolic risks, and osteoporosis is warranted.

\section{GCA}

GCA is a large vessel vasculitis, primarily affecting the aorta and its extracranial branches, with a predilection for the temporal artery. ${ }^{1}$ It commonly occurs in patients older than 50 years with highest incidence among people that are 70-79 years old. The incidence of GCA ranges between $6 / 100,000$ in northern Italy to $22 / 100,000$ in the UK. ${ }^{28-31}$

\section{Recognition and diagnosis of GCA}

EULAR and BSR updated their recommendations on diagnosis and treatment of GCA in 2018 and 2020, respectively. ${ }^{32,33}$

GCA is distinguished into three phenotypes: cranial GCA, large vessel GCA (LV-GCA) and isolated polymyalgia rheumatica (PMR). Patients aged over 50 years, presenting with abrupt-onset headache, scalp tenderness, visual loss, jaw claudication, limb claudication, polymyalgia or constitutional symptoms should raise suspicion of GCA. Several mimics of GCA and PMR (Table 4) should be excluded via thorough history, physical examination, and investigations (Tables 2 and 3; Fig 2). 2,34,35

High erythrocyte sedimentation rate (ESR) and C-reactive protein (CRP) are hallmarks of GCA. A small proportion of patients with GCA $(<4 \%)$ have normal ESR and CRP. ${ }^{36,37}$ Normal acute-phase reactants make a diagnosis of GCA very unlikely but do not rule it out.

\section{Confirmatory diagnostic test for GCA}

The latest recommendations advocate utilising either temporal artery biopsy (TAB) or ultrasound of the temporal and/or axillary arteries to confirm diagnosis of GCA. ${ }^{32,33,38}$

Table 4. Mimics of giant cell arteritis and polymyalgia rheumatica

Mimics of giant cell arteritis

Sinusitis

Dental or temporomandibular local disease Non-arteritic anterior ischaemic optic neuropathy Subacute thyroiditis Chronic infections Trigeminal neuralgia Malignancy artherosclerotic cardiovascular disease
Mimics of polymyalgia rheumatica

Elderly-onset rheumatoid arthritis Osteoarthritis Fibromyalgia Shoulder bursitis / tendonitis Cervical spondylosis Ankylosing spondylitis Statin-induced myositis Systemic lupus erythematosus Hypothyroidism Chronic infections Polymyositis Malignancy (eg multiple myeloma) Amyloidosis 
TAB has been regarded as the gold standard to diagnose GCA for decades. In one meta-analysis of studies investigating TAB positivity among patients satisfying the 1990 American College of Rheumatology classification criteria of GCA, the estimated sensitivity of TAB for GCA diagnosis was $77 \%$, with high betweenstudy heterogeneity. ${ }^{39,40}$

\section{Vascular imaging as an emerging diagnostic tool for GCA}

High-resolution colour Doppler ultrasound (CDS) of the temporal or axillary arteries, showing concentric hypoechoic mural thickening 'halo sign', and 'compression sign' where the hypoechoic wall swelling is non-compressible upon application of pressure with ultrasound probe, are the most important sonographic abnormalities for GCA. ${ }^{41}$ These findings are interpreted as inflammatory vessel wall oedema. ${ }^{42}$ Using CDS, LV-GCA was observed in 53\% of one GCA cohort, where circumferential, homogeneous, hypoechogenic mural thickening was most frequently observed in the axillary arteries. ${ }^{43}$ In the TABUL study, CDS of temporal and axillary arteries had a higher sensitivity than $\operatorname{TAB}(54 \%$ vs $39 \%$ ) but lower specificity ( $81 \%$ vs $100 \%$ ) in diagnosing GCA. ${ }^{44}$ In short, CDS of temporal or axillary arteries, best done within 1 week of glucocorticoid initiation, is valuable to confirm GCA in high probability cases. ${ }^{32}$

High-resolution magnetic resonance imaging (MRI) of cranial arteries can be considered as an alternative to CDS for GCA diagnosis. ${ }^{32,33,38}$ MRI can detect vessel wall oedema and contrast enhancement, signifying vessel inflammation. Using TAB as a reference standard, MRI of the cranial arteries had a sensitivity of $94 \%$ and specificity of $78 \%$ in diagnosing GCA. The corresponding negative predictive value of MRI cranial arteries was $98 \%$, thus potentially useful for ruling out GCA. ${ }^{45}$

Use of imaging to evaluate involvement of the aorta and its proximal branches in GCA is limited due to lack of direct evidence. Most of the published evidence is extrapolated from other diseases, such as Takayasu arteritis. ${ }^{38}$

Computed tomography angiography of the aorta and its major branches can reveal vessel wall thickening with contrast enhancement, and structural lesions (stenosis, dilatation or aneurysms). ${ }^{46}$ Contrast-enhanced magnetic resonance angiography was found to reliably identify aortitis in large-vessel vasculitides but changes were very sensitive to glucocorticoids. ${ }^{47}$ Positron emission tomography - computed tomography (PET-CT) can demonstrate inflammatory cell infiltration of the aorta and its branches. ${ }^{48}$ It has the advantage of being additionally able to detect malignancy or occult infections. ${ }^{38}$

Conventional angiography is not recommended for the diagnosis of GCA because safer modalities available. It is mainly used for vascular intervention such as angioplasty or stenting. ${ }^{38}$

\section{Management of GCA}

Glucocorticoids remain the mainstay of treatment for GCA. Oral glucocorticoids at $1 \mathrm{mg} / \mathrm{kg} /$ day should be initiated immediately while referring patients for urgent specialist evaluation. ${ }^{32,33}$ Highdose glucocorticoids are continued until resolution of symptoms and normalisation of inflammatory markers. Despite the lack of data regarding the optimal duration of glucocorticoid therapy, BSR recommends to taper over 12-18 months, whereas EULAR advocates 24 months or more. ${ }^{32,33}$
A substantial number of patients with GCA have refractory or relapsing disease when glucocorticoids are tapered. They are conventionally treated with glucocorticoid dose escalation, which subjects them to excessive cumulative adverse effects of glucocorticoids. MTX might be combined with glucocorticoid taper for those at high risk of glucocorticoid toxicity or who relapse, however the evidence remains equivocal. ${ }^{49}$

Tocilizumab, an interleukin- 6 inhibitor, was approved for GCA by US and European regulatory authorities in 2017. In the GiACTA trial, 1 year of weekly tocilizumab plus 26-week prednisolone taper $(56 \%)$ had higher rate of sustained remission at 1 year, compared with placebo and 26 -week prednisolone taper (14\%) or 52 -week taper $(18 \% ; p<0.001) .{ }^{50}$ Results from 2-year longterm extension of GiACTA trial showed $47 \%$ of patients in weekly tocilizumab plus 26-week prednisolone taper maintained clinical remission, with similar safety profile compared with placebo and prednisolone taper. This arm of patients had the lowest cumulative glucocorticoid dose over the 3-year study. ${ }^{51}$ Subcutaneous tocilizumab 162 mg weekly has been approved by NHS England for patients with relapsing or refractory GCA for 1 year. ${ }^{52}$

Contrary to previous recommendations, anticoagulant, antiplatelet or cholesterol-lowering agents are now not routinely recommended for treatment of GCA unless indicated. ${ }^{32,33}$

\section{Summary}

Significant advancement has been made in the management of common vasculitides, especially for AAV and GCA. Diagnosis of PSV depends largely on excluding mimics and secondary vasculitis, recognising a combination of clinical, laboratory, histopathological and radiological features. Validated diagnostic criteria are much anticipated.

Intravenous CYC is favoured over oral CYC for AAV due to lower cumulative toxicity. RTX has provided a treatment revolution for AAV, both for remission induction and maintenance, among patients with organ-threatening, life-threatening or relapsing disease. There is still a lack of robust data to support the use of PLEX in imminent life-threatening AAV. More research is needed to guide treatment for refractory or relapsing $A A V$, and to identify biomarkers indicating a predisposition to poorly controlled disease.

CDS of temporal or axillary arteries has similar diagnostic value as TAB in diagnosis GCA. Tocilizumab provides an additional therapeutic option for relapsing or refractory GCA, lowering risk of glucocorticoid toxicity in susceptible patients. Further costeffectiveness analyses are needed to support the extension commissioning of tocilizumab in GCA.

\section{References}

1 Jennette JC, Falk R, Bacon P et al. 2012 revised international Chapel Hill Consensus Conference nomenclature of vasculitides. Arthritis Rheum 2013;65:1-11.

2 Zarka F, Veillette C, Makhzoum J-P. A review of primary vasculitis mimickers based on the Chapel Hill Consensus classification. Int J Rheumatol 2020;2020:8392542.

3 Noorduyn L, Torenbeek R, Van Der Valk P et al. Sinonasal nonHodgkin's lymphomas and Wegener's granulomatosis: a clinicopathological study. Virchows Archiv A 1991:418:235-40.

4 Craven A, Robson J, Ponte C et al. ACR/EULAR-endorsed study to develop Diagnostic and Classification Criteria for Vasculitis (DCVAS). Clin Exp Nephrol 2013;17:619-21. 
5 Pearce FA, Griffiths B, Mukhtyar C et al. Prevalence and mortality of ANCA-associated vasculitis in England. Rheumatology 2020; 59(Supplement_2):keaa111.77.

6 Ntatsaki E, Carruthers D, Chakravarty K et al. BSR and BHPR guideline for the management of adults with ANCA-associated vasculitis. Rheumatology 2014;53:2306-9.

7 Yates M, Watts R, Bajema I et al. EULAR/ERA-EDTA recommendations for the management of ANCA-associated vasculitis. Ann Rheum Dis 2016;75:1583-94.

8 McGeoch L, Twilt M, Famorca L et al. CanVasc recommendations for the management of antineutrophil cytoplasm antibodyassociated vasculitides. J Rheumatol 2016;43:97-120.

9 Souza AWSd, Calich AL, Mariz HdA et al. Recommendations of the Brazilian Society of Rheumatology for the induction therapy of ANCA-associated vasculitis. Rev Bras Reumatol Engl Ed 2017:57:5484-96.

10 de Groot K, Harper L, Jayne DR et al. Pulse versus daily oral cyclophosphamide for induction of remission in antineutrophil cytoplasmic antibody — associated vasculitis: a randomized trial. Ann Intern Med 2009;150:670-80.

11 Harper L, Morgan MD, Walsh $\mathrm{M}$ et al. Pulse versus daily oral cyclophosphamide for induction of remission in ANCA-associated vasculitis: long-term follow-up. Ann Rheum Dis 2012;71:955-60.

12 Stone JH, Merkel PA, Spiera R et al. Rituximab versus cyclophosphamide for ANCA-associated vasculitis. N Engl ] Med 2010;363:221-32.

13 Jones RB, Cohen Tervaert JW, Hauser T et al. Rituximab versus cyclophosphamide in ANCA-associated renal vasculitis. N Engl ] Med 2010;363:211-20.

14 Jones RB, Furuta S, Tervaert JWC et al. Rituximab versus cyclophosphamide in ANCA-associated renal vasculitis: 2-year results of a randomised trial. Ann Rheum Dis 2015;74:1178-82.

15 National Institute for Health and Care Excellence. Rituximab in combination with glucocorticoids for treating anti-neutrophil cytoplasmic antibody-associated vasculitis: Technology appraisal guidance [TA308]. NICE, 2014. www.nice.org.uk/guidance/ta308

16 Guerry M-JC], Brogan P, Bruce IN et al. Recommendations for the use of rituximab in anti-neutrophil cytoplasm antibody-associated vasculitis. Rheumatology 2011;51:634-43.

17 Merkel P, Jayne D, Yue H et al. OP0011 A randomized, double-blind, active-controlled study of avacopan in anti-neutrophil cytoplasmic antibody (ANCA)-associated vasculitis. Ann Rheum Dis 2020;79:8.

18 Jayne DR, Gaskin G, Rasmussen N et al. Randomized trial of plasma exchange or high-dosage methylprednisolone as adjunctive therapy for severe renal vasculitis. J Am Soc Nephrol 2007;18:2180-8

19 Walsh M, Merkel PA, Peh CA et al. Plasma exchange and glucocorticoids in severe ANCA-associated vasculitis. N Engl ] Med 2020;382:622-31

20 Faurschou M, Westman K, Rasmussen $\mathrm{N}$ et al. Brief report: Long-term outcome of a randomized clinical trial comparing methotrexate to cyclophosphamide for remission induction in early systemic antineutrophil cytoplasmic antibody-associated vasculitis. Arthritis Rheum 2012;64:3472-7.

21 Jones RB, Hiemstra TF, Ballarin ] et al. Mycophenolate mofetil versus cyclophosphamide for remission induction in ANCAassociated vasculitis: a randomised, non-inferiority trial. Ann Rheum Dis 2019;78:399-405.

22 Guillevin L, Pagnoux C, Karras A et al. Rituximab versus azathioprine for maintenance in ANCA-associated vasculitis. $N$ Engl J Med 2014;371:1771-80.

23 Terrier B, Pagnoux C, Perrodeau É et al. Long-term efficacy of remission-maintenance regimens for ANCA-associated vasculitides. Ann Rheum Dis 2018;77:1150-6.

24 Smith R, Jayne D, Merkel P. LB004 A randomized, controlled trial of rituximab versus azathioprine after induction of remission with rituximab for patients with ANCA-associated vasculitis and relapsing disease. Nephrology Dialysis Transplantation 2020;35(Supplement_3):gfaa146.LB004.

25 Tieu J, Smith R, Basu N et al. Rituximab for maintenance of remission in ANCA-associated vasculitis: expert consensus guidelines. Rheumatology 2020;59:e24-32.

26 Metzler C, Miehle N, Manger K et al. Elevated relapse rate under oral methotrexate versus leflunomide for maintenance of remission in Wegener's granulomatosis. Rheumatology (Oxford) 2007:46:1087-91.

27 Specks U, Merkel PA, Seo P et al. Efficacy of remission-induction regimens for ANCA-associated vasculitis. N Engl J Med 2013:369:417-27.

28 Smeeth L, Cook C, Hall AJ. Incidence of diagnosed polymyalgia rheumatica and temporal arteritis in the United Kingdom, 19902001. Ann Rheum Dis 2006;65:1093-8.

29 Catanoso M, Macchioni P, Boiardi L et al. Incidence, prevalence, and survival of biopsy-proven giant cell arteritis in northern Italy during a 26-year period. Arthritis Care Res (Hoboken) 2017:69:430-8.

30 Mohammad AJ, Nilsson J-Å, Jacobsson LT, Merkel PA, Turesson C. Incidence and mortality rates of biopsy-proven giant cell arteritis in southern Sweden. Ann Rheum Dis 2015;74:993-7.

31 Nesher G, Ben-Chetrit E, Mazal B, Breuer GS. The incidence of primary systemic vasculitis in Jerusalem: a 20-year hospital-based retrospective study. J Rheumatol 2016:43:1072-7.

32 Mackie SL, Dejaco C, Appenzeller S et al. British Society for Rheumatology guideline on diagnosis and treatment of giant cell arteritis. Rheumatology 2020;59:e1-23.

33 Hellmich B, Agueda A, Monti S et al. 2018 Update of the EULAR recommendations for the management of large vessel vasculitis Ann Rheum Dis 2020;79:19-30.

34 Nesher G, Breuer GS. Giant cell arteritis and polymyalgia rheumatica: 2016 update. Rambam Maimonides Med J 2016;7:e0035

35 Dasgupta B. Concise guidance: diagnosis and management of polymyalgia rheumatica. Clin Med 2010;10:270.

36 Kermani TA, Schmidt J, Crowson CS et al. Utility of erythrocyte sedimentation rate and $\mathrm{C}$-reactive protein for the diagnosis of giant cell arteritis. Semin Arthritis Rheum 2012;41:866-71.

37 Parikh M, Miller NR, Lee AG et al. Prevalence of a normal C-reactive protein with an elevated erythrocyte sedimentation rate in biopsyproven giant cell arteritis. Ophthalmology 2006;113:1842-5.

38 Dejaco C, Ramiro S, Duftner C et al. EULAR recommendations for the use of imaging in large vessel vasculitis in clinical practice. Ann Rheum Dis 2018;77:636-43.

39 Hunder GG, Bloch DA, Michel BA et al. The American College of Rheumatology 1990 criteria for the classification of giant cell arteritis. Arthritis Rheum 1990;33:1122-8.

40 Rubenstein E, Maldini C, Gonzalez-Chiappe S, Chevret S, Mahr A. Sensitivity of temporal artery biopsy in the diagnosis of giant cell arteritis: a systematic literature review and meta-analysis. Rheumatology 2020;59:1011-20.

41 Chrysidis S, Duftner C, Dejaco C et al. Definitions and reliability assessment of elementary ultrasound lesions in giant cell arteritis: a study from the OMERACT Large Vessel Vasculitis Ultrasound Working Group. RMD Open 2018;4:e000598.

42 Schmidt WA, Kraft HE, Vorpahl K, Völker L, Gromnica-Ihle EJ. Color duplex ultrasonography in the diagnosis of temporal arteritis. $\mathrm{N}$ Engl J Med 1997;337:1336-42.

43 Czihal M, Zanker S, Rademacher A et al. Sonographic and clinical pattern of extracranial and cranial giant cell arteritis. Scand J Rheumatol 2012;41:231-6.

44 Luqmani R, Lee E, Singh S et al. The role of ultrasound compared to biopsy of temporal arteries in the diagnosis and treatment of giant cell arteritis (TABUL): a diagnostic accuracy and cost-effectiveness study. Health Technol Assess 2016;20:1-238.

45 Rhéaume M, Rebello R, Pagnoux C et al. High-resolution magnetic resonance imaging of scalp arteries for the diagnosis of giant cell 
arteritis: results of a prospective cohort study. Arthritis Rheum 2017;69:161-8.

46 Prieto-González S, Arguis P, García-Martínez A et al. Large vessel involvement in biopsy-proven giant cell arteritis: prospective study in 40 newly diagnosed patients using CT angiography. Ann Rheum Dis 2012;71:1170-6.

47 Adler S, Sprecher M, Wermelinger F et al. Diagnostic value of contrast-enhanced magnetic resonance angiography in largevessel vasculitis. Swiss Med Wkly 2017;147:w14397.

48 Besson FL, Parienti J], Bienvenu B et al. Diagnostic performance of 18 F-fluorodeoxyglucose positron emission tomography in giant cell arteritis: a systematic review and meta-analysis. Eur J Nucl Med Mol Imaging 2011;38:1764-72.

49 Mahr AD, Jover JA, Spiera RF et al. Adjunctive methotrexate for treatment of giant cell arteritis: an individual patient data metaanalysis. Arthritis Rheum 2007;56:2789-97.
50 Stone JH, Tuckwell K, Dimonaco S et al. Trial of Tocilizumab in giant-cell arteritis. N Engl J Med 2017;377:317-28.

51 Stone JH, Bao M, Han J et al. OP0140 Long-term outcome of tocilizumab for patients with giant cell arteritis: results from part 2 of the GiACTA trial. Ann Rheum Dis 2019;78:145-146.

52 National Institute for Health and Care Excellence. Tocilizumab for treating giant cell arteritis: Technology appraisal guidance [TA518]. NICE, 2018 www.nice.org.uk/guidance/ta518

Address for correspondence: Prof Robert J Moots, Department of Rheumatology, Aintree University Hospital, Longmoor Lane, Liverpool L9 7AL, UK.

Email: robert.moots@liverpoolft.nhs.uk

\section{Mental health and wellbeing resource}

This online resource aims to shine a spotlight on the mental health and wellbeing of physicians by opening up the conversation about mental health issues and their impact.

It will help you recognise the warning signs in yourself and others, as well as know about the steps you can take to stay well and seek the right support when you need it.

www.rcplondon.ac.uk/wellbeing

(n) 